REVISTA ESTUDOS POLÍTICOS Vol. 9|N.1 ISSN 2177-2851

\title{
Editorial Novos e antigos populismos em debate: comparações, dissensos e pertinências.
}

Se é possível dizer que ao longo das últimas décadas o conceito de "populismo" permaneceu um tanto quanto secundarizado no debate público, nos últimos tempos ele talvez seja uma das categorias mais utilizadas não apenas nas produções acadêmicas, mas, sobretudo, nas discussões políticas. É quase impossível abrir um jornal hoje de qualquer parte do mundo e não encontrar uma reportagem ou um editorial, abordando a expansão de movimentos e governantes comumente chamados de "populistas". Ressaltese, desde já, que esta mobilização do conceito tem se dado na maior parte das vezes sem qualquer cuidado epistemológico. Recorre-se, com frequência, ao termo populismo mais como uma acusação retórica contra aquele adversário com o qual não se concorda política e ideologicamente, do que a partir de uma sustentação teórica sobre o real significado do termo.

Fato é que os últimos anos têm testemunhado a ascensão, à direita e à esquerda, de vários governantes e movimentos aos quais têm sido designados com o epíteto de populistas. Se o termo já era utilizado em períodos anteriores principalmente em relação a governantes e movimentos ligados ao campo da esquerda, como Hugo Chávez, Evo Morales e Lula, em tempos mais recentes, sobretudo no contexto que se seguiu à crise econômica de 2008 e 2009, o termo passou a ser mobilizado também para se referir a vários governantes mais conservadores que ascenderam ao poder em diferentes partes do mundo, como Donald Trump, nos Estados Unidos, Viktor Orban, na Hungria, Jair Bolsonaro, no Brasil, além de movimentos políticos, com destaque para aquele que impulsionou o chamado "Brexit", no Reino Unido, e o que possibilitou fortalecimento do Movimento 5 Estrelas, na Itália.

Em diálogo com esse contexto, várias publicações na imprensa passaram a abordar o "fenômeno populista", com o intuito de melhor compreendê-lo, a exemplo de uma série recente lançada pelo jornal inglês The Guardian, que destaca que o número de europeus votando em partidos populistas ampliou de 7\% para 25\% ao longo das duas últimas décadas. Além disso, várias foram as obras publicadas nos últimos anos buscando compreender este fenômeno político e sociológico, como What is Populism?, de JeanWerner Müller (2016), The Populist Explosion, de John B. Judis (2016), The Oxford Handbook of Populism, organizado, entre outros, por Cristobal Rovira Kaltwasser (2017), The Global Rise of Populism: Performance, Political Style, and Representation, de Benjamin Moffitt (2017), From Fascism to Populism in History, de Federico Finchelstein (2017), The Populist Temptation: Economic Grievance and Political Reaction in the Modern Era, de Barry Eichengreen (2018) e National Populism: The Revolt Against Liberal Democracy, de Robert Eatwell e Matthew Goodwin (2018). 
Quer seja nas publicações de jornais, quer seja nos livros recentemente lançados, é possível perceber uma enorme heterogeneidade nas abordagens construídas sobre a definição do que é o populismo e acerca de quais tipos de movimentos e governantes podem ser assim designados. De todo modo, apesar dessas diferenças, essas publicações se aproximam no sentido de perceber uma mudança no Zeitgeist político, com a consolidação e a expansão de atores e grupos políticos, à esquerda e à direita, que portam uma retórica que converge no sentido de problematizar e denunciar as instituições políticas liberais, as "elites" e os partidos tradicionais, sustentando discursos antissistemas - em alguns casos progressistas, em outros, abertamente reacionários -, que defendem agendas que se colocam contra o establishment político consolidado ao longo dos últimos anos em diferentes países e, em muitos ocasiões, ancorados em uma retórica nacionalista crítica aos efeitos da globalização.

O presente dossiê, intitulado "Novos e antigos populismos em debate: comparações, dissensos e pertinências", procura contribuir com a discussão atual em torno do populismo. Para tanto, alguns dos textos aqui reunidos se dedicam tanto a uma abordagem teórica mais ampla do conceito, estabelecendo um diálogo direto com autores que se debruçaram sobre esta categoria ao longo dos últimos anos, quanto a uma investigação mais empírica, que lança olhares plurais sobre experiências diversas de experiências "populistas". A exposição combinada de artigos mais teóricos e outros mais empíricos possibilita um olhar e uma compreensão multifacetada e mais refinada das diferentes interpretações que se tem da ideia de populismo.

Os artigos que abrem o dossiê - "A trajetória de uma noção polêmica: análise crítica do populismo na teoria política de Ernesto Laclau" e o "O populismo na perspectiva de Ernesto Laclau: uma alternativa para a esquerda?", "O populismo além de Laclau: uma abordagem normativa" - se dedicam a esta busca teórica por uma compreensão mais alargada do conceito de populismo. Em diálogo com autores diversos como Laclau, Foucault e Rancière, os autores desses trabalhos, a partir de perspectivas diversas, procuram refletir de forma mais ampla não apenas sobre a categoria populismo em si, mas acerca de termos a ele muitas vezes associados, como, por exemplo, "povo" e "plebe", além de analisarem de que maneira essas discussões se conectam com debates relacionados às instituições, às relações de poder e às formas de dominação.

Os demais artigos do dossiê se voltam mais diretamente para a análise de experiências históricas específicas, com o intuito de refletir acerca das possibilidades da mobilização da categoria populismo para a compreensão de situações concretas, a exemplo do artigo "Populismo de esquerda versus populismo de direita no século XXI: o conflito". Nessa perspectiva, os textos aqui publicados, além de abordarem as relações das redes sociais e mídias contemporâneas com o fenômeno do populismo - como ocorre com o trabalho "Mais populismo, menos representatividade: monitoramento e lógica populista da comunicação política em redes sociais online" -, acabam por abarcar tanto as experiências dos Estados Unidos e de países europeus - a exemplo dos artigos "Um debate sobre o fenômeno do populismo na Europa Central", "Populismo de esquerda versus populismo de direita no início do século XXI: o conflito político nos EUA, Inglaterra, França e Alemanha" e "Contemporary extreme right parties in Europe: definition and electoral performance" -, quanto aquelas de países "periféricos" do sistema capitalista, com destaque para os artigos "O MNR e a Revolução de 1952", "Pensar os populismos nas Guianas" e "Aquém do lulismo: notas críticas sobre a atual reprodução do paradigma do populismo por filósofos políticos brasileiros". 
A diversidade e a pluralidade de abordagens, temáticas, enfoques e vieses analíticos dos doze artigos reunidos no presente dossiê evidenciam as múltiplas possibilidades de compreensão do chamado "populismo". A expectativa é a de que os textos aqui reunidos possam contribuir para uma reflexão mais ampla e sofisticada acerca de todas as questões relacionadas com a temática "populista", não apenas do ponto de vista teórico, mas, sobretudo, político. Conforme busquei chamar a atenção no início desta apresentação, o termo populismo, para além das questões acadêmicas, assumiu um lugar de destaque no debate público e pensar politicamente sobre ele é fundamental para todos aqueles que buscam, de alguma forma, se engajar nos embates contra as diversas manifestações de autoritarismo no mundo contemporânea e a favor da ampliação da democracia.

O dossiê "Novos e antigos populismos em debate: comparações, dissensos e pertinências" vem acompanhado de uma entrevista com Cesar Guimarães, professor do Instituto de Estudos Sociais e Políticos, da Universidade do Estado do Rio de Janeiro (IESP-UERJ). A entrevista, realizada por Thais Florêncio Aguiar - que será em breve publicada no livro Cesar Guimarães, uma antologia de textos políticos, organizado por Thais Florêncio Aguiar, Cristina Buarque de Hollanda e Pedro Villas Bôas Castelo Branco - aborda aspectos diversos da história brasileira e da conjuntura política do país, contribuindo para um entendimento mais amplo sobre os defafios colocados no tempo presente.

Boa leitura!

\section{Fernando Perlatto ${ }^{1}$}

\footnotetext{
${ }^{1}$ Professor do Departamento de História e do Programa de Pós-Graduação em História da Universidade Federal de Juiz de Fora (UFJF). Possui graduação em História pela UFJF, Mestrado em Sociologia pelo Instituto Universitário de Pesquisas do Rio de Janeiro (IUPERJ) e Doutorado em Sociologia pelo Instituto de Estudos Sociais e Políticos (IESP-UERJ). Foi Pesquisador Visitante da New York University (NYU). É autor dos livros A imaginação sociológica brasileira: a sociologia no Brasil e sua vocação pública (CRV, 2016) e As esferas públicas no Brasil: teoria social, públicos subalternos e democracia (Appris, 2018), e organizou com Daniel Chaves a coletânea Repensar os populismos na América do Sul: debates, tradições e releituras (Autografia/UNIFAP, 2016).
} 
Vol. $9 \mid$ N. 1

Editorial [1 - 4]

Entrevistas

Interviews

Artigos

Articles
Entrevista com Cesar Guimarães [X-XX]

Thais Florêncio de Aguiar

A trajetória de uma noção polêmica: analise crítica do populismo na teoria política de Ernesto Laclau [X-XX]

Felipe Linden

O populismo na perspectiva de Ernesto Laclau: uma alternativa para a esquerda? $[\mathrm{XX}-\mathrm{XX}]$

Kamila Lima do Nascimento

O populismo para além de Laclau: uma abordagem normativa $[\mathrm{XX}-\mathrm{XX}]$

Mayra Goulart

Populismo de esquerda versus populismo de direita no século XXI: o conflito [XX-XX]

Theófilo Machado Rodriguês

Mais populismo, menos representatividade: monitoramento e lógica populista da comunicação política em redes sociais online $[X X-X X X]$

Fernanda Cavassana e Emerson Urizzi Cervi

Um debate sobre o fenômeno do populismo na Europa Central [XXX-XXX]

Flavio Rodriguês Barbosa

Contemporary extreme right parties in Europe: definition and electoral performance $[\mathrm{XXX}-\mathrm{XXX}]$

Aline Burni

O MNR e a Revolução de 1952 [XXX-XXX]

João Paulo Viana

Pensar o populismo nas Guianas [XXX-XXX]

luri Cavlak

Aquém do lulismo: notas críticas sobre a atual reprodução do paradigma do populismo por filósofos políticos brasileiros $[\mathrm{XXX}-\mathrm{XXX}]$

Pedro Lima e Josué Medeiros 